\title{
Anterior STEMI associated with decreased strain in remote cardiac myocardium
}

\author{
Hannah Sjögren ${ }^{1}$ Ulrika Pahlm ${ }^{1,2} \cdot$ Henrik Engblom $^{1} \cdot$ David Erlinge $^{3} \cdot$ Einar Heiberg ${ }^{1} \cdot$ Håkan Arheden $^{1}$. \\ Marcus Carlsson ${ }^{1} \cdot$ Ellen Ostenfeld ${ }^{1,4}$ (D)
}

Received: 7 April 2021 / Accepted: 21 August 2021 / Published online: 5 September 2021

(c) The Author(s) 2021

\begin{abstract}
To assess (1) global longitudinal strain (GLS) by feature tracking cardiac magnetic resonance (CMR) in the sub-acute and chronic phases after ST-elevation infarction (STEMI) and compare to GLS in healthy controls, and (2) the evolution of GLS and regional longitudinal strain (RLS) over time, and their relationship to infarct location and size. Seventy-seven patients from the CHILL-MI-trial (NCT01379261) who underwent CMR 2-6 days and 6 months after STEMI and 27 healthy controls were included for comparison. Steady state free precession (SSFP) long-axis cine images were obtained for GLS and RLS, and late gadolinium enhancement (LGE) images were obtained for infarct size quantifications. GLS was impaired in the sub-acute $(-11.8 \pm 3.0 \%)$ and chronic phases $(-14.3 \pm 2.9 \%)$ compared to normal GLS in controls $(-18.4 \pm 2.4 \% ; \mathrm{p}<0.001$ for both). GLS improved from sub-acute to chronic phase $(\mathrm{p}<0.001)$. GLS was to some extent determined by infarct size (sub-acute: $\mathrm{r}^{2}=0.2$; chronic: $\mathrm{r}^{2}=0.2, \mathrm{p}<0.001$ ). RLS was impaired in all 6 wall-regions in LAD infarctions in both the subacute and chronic phase, while LCx and RCA infarctions had preserved RLS in remote myocardium at both time points. Global longitudinal strain is impaired sub-acutely after STEMI and improvement is seen in the chronic phase, although not reaching normal levels. Global longitudinal strain is only moderately determined by infarct size. Regional longitudinal strain is most impaired in the infarcted region, and LAD infarctions have effects on the whole heart. This could explain why LAD infarcts are more serious than the other culprit vessel infarctions and more often cause heart failure.
\end{abstract}

Keywords Longitudinal strain $\cdot$ ST-elevation infarction $\cdot$ Cardiac magnetic resonance $\cdot$ Feature tracking $\cdot$ Culprit vessel · Infarct size

$\begin{array}{ll}\text { Abbreviations } \\ \text { CMR } & \text { Cardiac resonance imaging } \\ \text { EF } & \text { Ejection fraction } \\ \text { GLS } & \text { Global longitudinal strain }\end{array}$

Ellen Ostenfeld

ellen.ostenfeld@med.lu.se

Hannah Sjögren

hannahsjogren1@gmail.com

Ulrika Pahlm

ulrika.pahlm@skane.se

Henrik Engblom

henrik.engblom@med.lu.se

David Erlinge

david.erlinge@med.lu.se

Einar Heiberg

einar.heiberg@med.lu.se

Håkan Arheden

hakan.arheden@med.lu.se

$\begin{array}{ll}\text { LAD } & \text { Left anterior descending artery } \\ \text { LC }_{\mathrm{x}} & \text { Left circumflex artery } \\ \text { LGE } & \text { Late gadolinium enhancement } \\ \text { LS } & \text { Longitudinal strain }\end{array}$

Marcus Carlsson

marcus.carlsson@med.lu.se

1 Department of Clinical Sciences Lund, Clinical Physiology, and Skane University Hospital, Lund University, Lund, Sweden

2 Department of Clinical Sciences Lund, and Anesthesia and Invasive Care, Helsingborg Hospital, Lund University, Lund, Sweden

3 Department of Clinical Sciences Lund, Cardiology, and Skane University Hospital, Lund University, Lund, Sweden

4 Department of Clinical Physiology, Skåne University Hospital, 22185 Lund, Sweden 


$\begin{array}{ll}\text { LV } & \text { Left ventricular } \\ \text { RCA } & \text { Right coronary artery } \\ \text { RLS } & \text { Regional longitudinal strain } \\ \text { SSFP } & \text { Steady state free precession } \\ \text { STEMI } & \text { ST-elevation infarction } \\ \text { SV } & \text { Stroke volume }\end{array}$

\section{Introduction}

Survival rates after ST-elevation myocardial infarction (STEMI) have improved substantially over the last decades, however both morbidity and mortality remain high [1-3]. Left ventricular (LV) dysfunction and heart failure are common consequences of STEMI and lead to increased mortality $[4,5]$. Thus, there is a need to evaluate LV function with high precision to assess the disease progress and to guide in the use of therapeutic interventions. LV ejection fraction (EF) is the standard marker for systolic function [6], but fails to detect subtle changes in myocardial contractility [7]. Recent studies have suggested global longitudinal strain (GLS) as a measure of dysfunction, especially when EF remains normal [8-10].

Echocardiography is the first-line modality to assess cardiac function and strain [11], and GLS assessed by speckle tracking echocardiography has prognostic implications $[8$, 12-16]. The acoustic window can be an acquisitional challenge and hence strain analysis done with this technique can be unreliable. Cardiac magnetic resonance (CMR) is the gold standard for volumetric and functional assessment owing to the high precision, accuracy and reproducibility [17]. Feature tracking (FT) enables strain assessment from standard cine CMR images without the need for special sequences [18]. The clinical importance of GLS assessment from FT-CMR has been shown as an independent predictor for major adverse cardiac event $[9,19]$. Further, GLS from FT-CMR has added prognostic value to quantifying infarct size (IS) and EF for all-cause mortality [9] and has been presented as a strong and independent predictor of major adverse cardiac events in patients with STEMI [20].

GLS has been studied in the acute phase and at follow up in patients with STEMI using echocardiography [21, 22] and in patients with anterior infarctions using FT-CMR [23]. However, it is unknown how the location of the STEMI, defined by culprit lesion coronary perfusion territory, affect GLS assessed with FT-CMR. Furthermore, it is not known how regional longitudinal strain (RLS) using FT-CMR is affected in the culprit vessel myocardial territory compared to remote territory in the sub-acute phase or how RLS affected in the chronic phase.

We have previously shown that atrioventricular plane displacement is decreased in both the sub-acute and chronic phases after STEMI, resulting in a decreased longitudinal contribution to stroke volume in both phases [24-26]. While longitudinal contribution to stroke volume reflects the volumetric results of the contraction, longitudinal strain measures deformation at a myocardial level.

Therefore, the aims of this study were: (1) to assess GLS with FT-CMR 2-6 days (sub-acute phase) and 6 months (chronic phase) after STEMI compared with healthy controls, and (2) to investigate the evolution of GLS and regional longitudinal strain (RLS) over time, and their relationship to infarct location and size assessed by CMR.

\section{Methods}

\section{Study population}

Patients from the multi-centre cardio-protection trial CHILL-MI (ClinicalTrials.gov NCT01379261) constituted the study population for this study [27]. In short, patients were over 18 years old, presented with chest pain lasting for less than $6 \mathrm{~h}$, had their first STEMI and underwent subsequent percutaneous coronary intervention with successful reperfusion of the occluded vessel. The patients included in this study $(\mathrm{n}=77)$ underwent a CMR examination within 2-6 days after STEMI and a follow-up CMR 6 months later. For comparison, 27 healthy, age-matched controls used in previous studies in our research group, were included $[24,28]$.

\section{CMR image acquisition}

Patients underwent CMR at one of multiple European centres using two different vendors: Philips Healthcare (Best, The Netherlands) or Siemens AG (Erlangen, Germany). Steady state free precession (SSFP) cine images in short-axis view (base to apex) and in 2-, 3- and 4-chamber long-axis views were acquired. Typical image parameters: 20-30 time frames per cardiac cycle, retrospectively ECG gated, $8 \mathrm{~mm}$ slice thickness (no gap) with in-plane resolution $1.5 \times 1.5 \mathrm{~mm}$ covering the entire left ventricle.

Late gadolinium enhancement (LGE) images were acquired 15-20 min after gadolinium-based contrast agent $(0.2 \mathrm{mmol} / \mathrm{kg})$ injection in the corresponding short- and long-axis view as for the SSFP cine imaging. All images were obtained at end-expiratory breath-hold with patients in supine position. Typical image parameters: prospective ECG gating with $8 \mathrm{~mm}$ slice thickness (no gap) with in-plane resolution was $1.5 \times 1.5 \mathrm{~mm}$. Inversion time was chosen to null remote myocardium [29]. 


\section{Image analysis}

\section{Baseline data}

All CMR image analysis was performed using a freely available software for baseline data and infarct size (Segment v1.9 R3084, Medviso, Lund, Sweden) [30] and for strain analysis (Segment v2.2 R6887, Medviso, Lund, Sweden). Delineations of the endo- and epicardium of the LV in short axis cine images in end-diastole and end-systole were made by expert readers (MC, HA, HE) in a core lab setting (Imacor AB, Lund, Sweden) from which LV end-diastolic and end-systolic volumes were computed. LV mass was calculated as epicardial volume subtracted with the endocardial volume and multiplied with the muscle density $(1.05 \mathrm{~g} / \mathrm{ml})$.

\section{Infarct size}

Short-axis LGE images were used to quantify infarct size with a previously validated semi-automatic method using an automatic threshold computation followed by post processing to remove spurious infarct regions and a weighted summation to account for partial volume effects [31], where the endo- and epicardium were manually traced after which a computer algorithm calculated the hyper-enhanced myocardium (MC, HA, HE) (Fig. 1). Manual adjustments were then made when necessary. Infarct size was expressed as percentage of the total LV myocardial volume. Infarct extent was expressed as the proportion of endocardium involved in the infarction in relation to the total $\mathrm{LV}$ endocardial surface as previously described [32]. Remote myocardium was defined as absence of infarction assessed by LGE $[25,33]$. Infarct transmurality was expressed in percentage and calculated as the amount of infarcted myocardium divided by the myocardial volume, taken over the area of infarction. Amount of infarcted myocardium was also here computed with weighted algorithm [31].

\section{Longitudinal Strain}

Peak longitudinal strain was analysed both for GLS and RLS in the three long-axis (2-, 3-, and 4-chamber view) cine SSFP images using feature tracking (Fig. 1). Delineations along the epi- and endocardial borders of the myocardium were drawn manually in end-diastole with automated propagation of the myocardial movement throughout the cardiac cycle using a vector-based algorithm [34]. Manual adjustments of the delineations were applied in end-diastole if the automated propagation did not comply properly through systole.
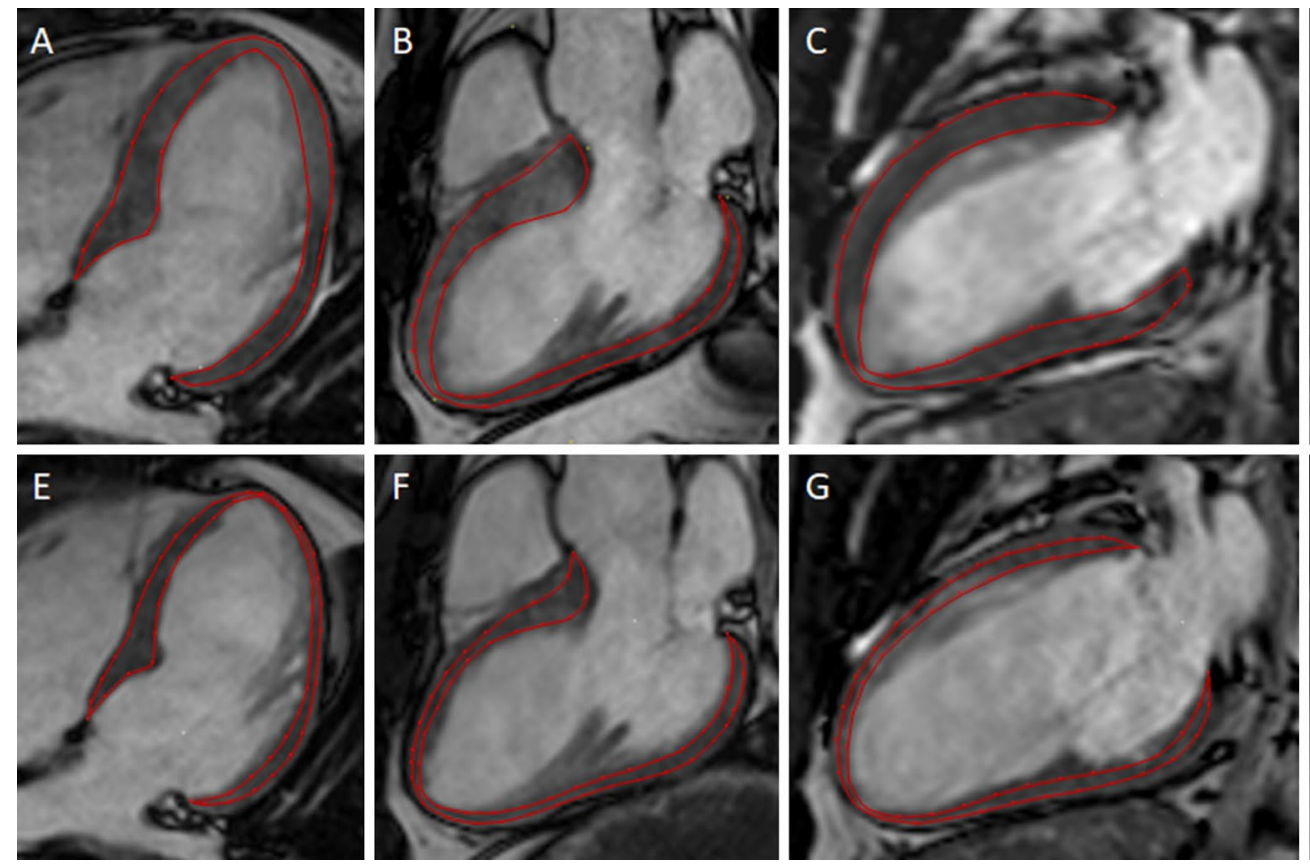
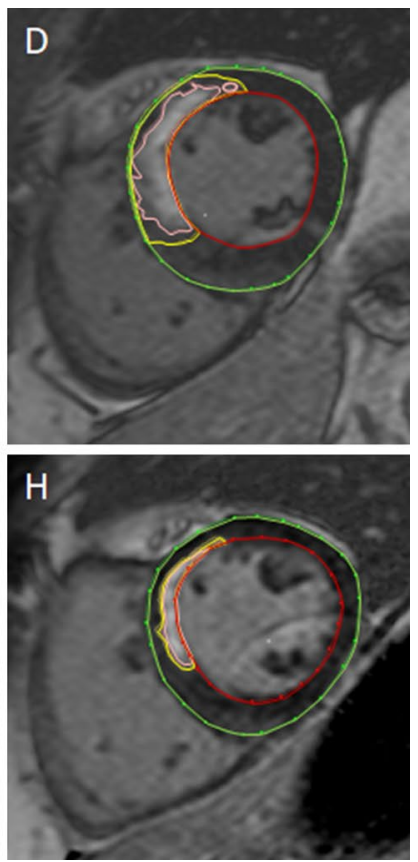

Fig. 1 Example of strain and infarct delineations in a patient with STEMI in the LAD in the sub-acute (top row) and chronic (bottom row) phase. A-D show a patient in the sub-acute phase (2-6 days) after ST-elevation myocardial infarction (STEMI) in the left anterior descending artery (LAD), and $\mathbf{E}-\mathbf{H}$ show the same patient in the chronic phase 6 months after the STEMI. The end-diastolic delinea- tions of the left ventricular myocardial borders in red are illustrated in the 4-chamber view $(\mathbf{A}, \mathbf{E}), 3$-chamber view $(\mathbf{B}, \mathbf{F})$ and 2-chamber view $(\mathbf{C}, \mathbf{G})$. Infarct delineation is illustrated in one midventricular short-axis late gadolinium enhancement image $(\mathbf{D}, \mathbf{H})$ with epicardial contour (green), endocardial contour (red), extent infarction (pink) and core of infarction (yellow) 
All images were surveyed by one experienced reader (HS) and adjusted by a second expert reader (EO) as adjudicator when needed. If tracking was still inadequate, segments of this view was excluded, and the two remaining views were used for calculations.

Longitudinal strain values were extracted both as an average of the whole LV (GLS) and in 17 LV segments based on American Heart Association's segmentation model [22]. RLS was compared among patient subgroups divided by STEMI culprit vessel [left anterior descending artery (LAD), left circumflex artery (LCx) and right coronary artery (RCA)].

When assessing RLS, the segments were grouped into six anatomical wall regions: anterior, anterolateral, inferolateral, inferior, inferoseptal and anteroseptal wall. Apical segments and the apex (segment 17) were excluded for RLS comparisons as LAD infarctions often has a "wrap around" infarction with larger involvement of apical segments compared to LCx and RCA infarctions.

\section{Statistics}

Continuous data was expressed as mean \pm SD. Categorical data was expressed in absolute numbers and proportion in percentage. Student's t-test and Fisher's Exact test were used for comparison between all patients and controls. Comparisons between the sub-acute and chronic phase for all patients were made with paired Student's t-test. Coefficient of determination was calculated from Pearson's correlation. Subgroup analyses by culprit vessel was-owing to non-normal distribution assessed by histograms-performed with Mann-Whitney U-test for comparison to controls, Wilcoxon Signed Ranks Test for comparison between the sub-acute and chronic phase and Kruskal-Wallis for multiple comparisons with Bonferroni's correction for multiple tests. Results with a two-sided $\mathrm{p}$-value $<0.05$ were considered statistically significant.

Statistical analyses were performed using SPSS (IBM Corp. Released 2017. IBM SPSS Statistics for Macintosh, Version 25.0. Armonk, NY: IBM Corp.) and GraphPad Prism (version 8.00 for Macintosh, GraphPad Software, San Diego, California USA). Radar charts were made in Microsoft Excel 2015.

\section{Results}

Seventy-seven patients $(58.2 \pm 10.2$ years $)$ and 27 age matched controls $(60.7 \pm 10.7$ years $)$ were included. At admission, none had prior myocardial infarction, percutaneous coronary intervention, coronary artery by-pass graft, or congested heart failure. One (1\%) had prior stroke, 8 (10\%) had known diabetes mellitus, 10 (13\%) had medication for hyperlipidaemia, and 20 (26\%) had antihypertensive medication. Twenty-seven (35\%) had other significant lesions than the culprit lesion. Data on medical therapy at follow-up was not available in this study. Patients were divided into groups according to culprit vessel $(\mathrm{LAD} n=27, \mathrm{LCx} n=10$ and RCA $n=39$ ). Figure 2 demonstrates the distribution of infarction on a group level for each culprit vessel in the subacute and chronic phase after STEMI. Subject characteristics are presented in Table 1. Patients and controls did not differ in age, but the patient group had a higher proportion of men than the control group. Weight and end-systolic volumes were higher and EF lower in patients than in controls. Of note, heart rate, LV mass and SV were altered in the subacute phase but normalised to the chronic phase to levels that are en par with the healthy controls.

\section{Global longitudinal strain (GLS)}

Four of 2172 segments were excluded owing to inadequate tracking. Table 2 shows GLS and IS for all patients and patients divided by subgroups as well as GLS for controls. Figure 3 shows the distribution and comparison between groups of IS and GLS. Infarct size was significantly larger within the first week of STEMI than six months after $(\mathrm{p}<0.001)$.

GLS was reduced both in the sub-acute and chronic phases compared to controls ( $p<0.001$ for both). GLS and EF improved from the sub-acute to the chronic phase (p<0.001) (Fig. 3).

IS and GLS had a modest, but significant coefficient of determination in both the sub-acute and chronic phases after STEMI as well as between IS and EF (Fig. 4). Likewise, there was a significant coefficient of determination between endocardial extent and transmurality of infarction and GLS in chronic phase $\left(\mathrm{r}^{2}=0.2, \mathrm{p}<0.001\right.$ for both) after STEMI and between endocardial extent and transmurality of infarction and EF in both phases (extent: sub-acute: $\mathrm{r}^{2}=0.3$ and chronic: $\mathrm{r}^{2}=0.3, \mathrm{p}<0.001$ for both; and transmurality: subacute: $\mathrm{r}^{2}=0.1, \mathrm{p}=0.03$ and chronic: $\mathrm{r}^{2}=0.2, \mathrm{p}<0.001$ ). There was, however, no significant coefficient of determination between endocardial extent or transmurality of infarction and GLS in the sub-acute phase (extent: $\mathrm{r}^{2}=0.01$, $\mathrm{p}=0.3$ and transmurality: $\mathrm{r}^{2}<0.001, \mathrm{p}=1.0$; respectively).

There was no difference in GLS in the sub-acute phase between patients with or without diabetes $(p=0.4)$, with or without antihypertensive medication $(p=0.08)$, or with or without lipid lowering medication $(\mathrm{p}=0.2)$ at admission. Patients with other significant lesions than culprit lesion had lower GLS than those with only one lesion in the subacute phase $(-10.8 \%$ vs $-12.3 \%, p=0.04)$, while there was no difference in GLS the chronic phase between the groups $(-14.2 \%$ vs $-14.3 \%, \mathrm{p}=0.7)$. 


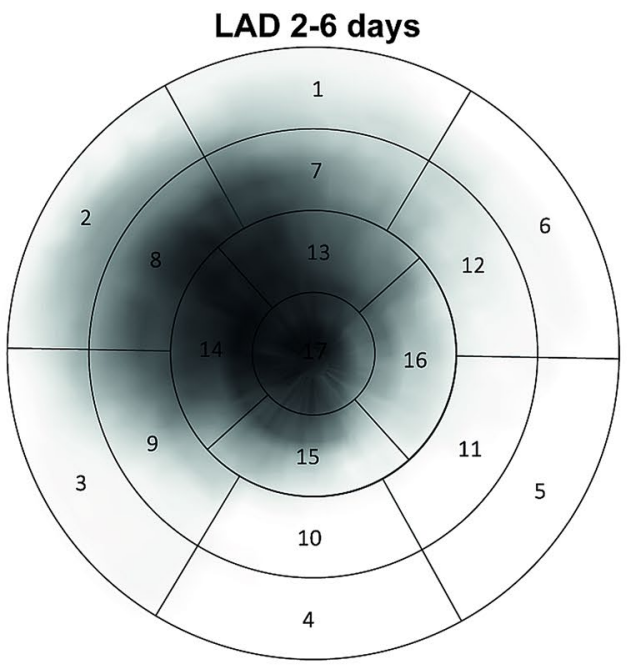

LCx 2-6 days

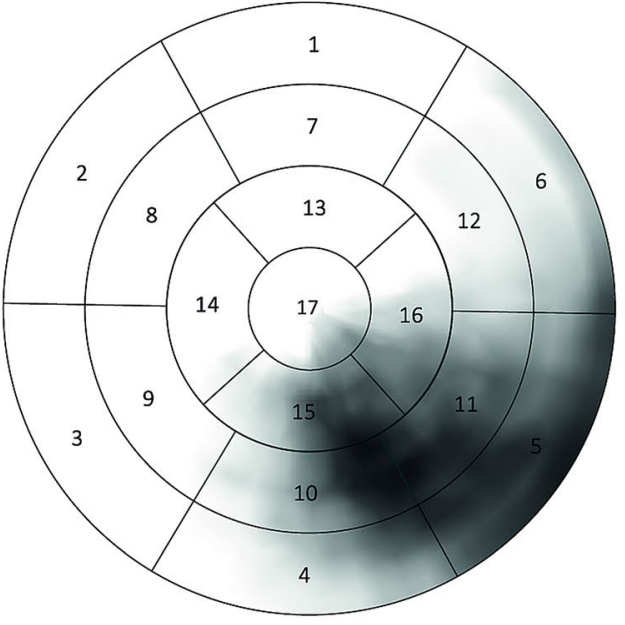

RCA 2-6 days

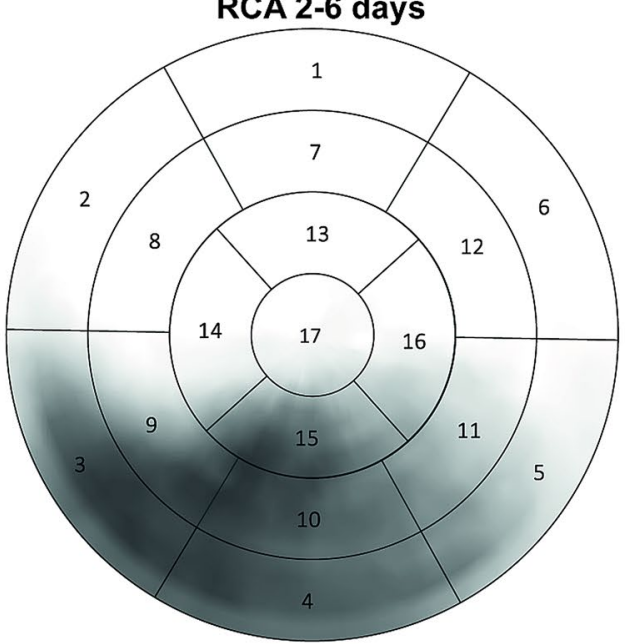

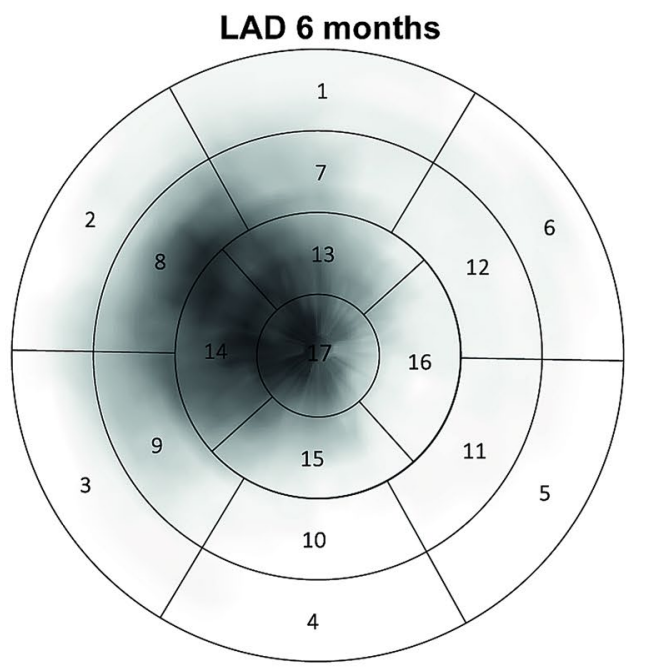

LCx 6 months

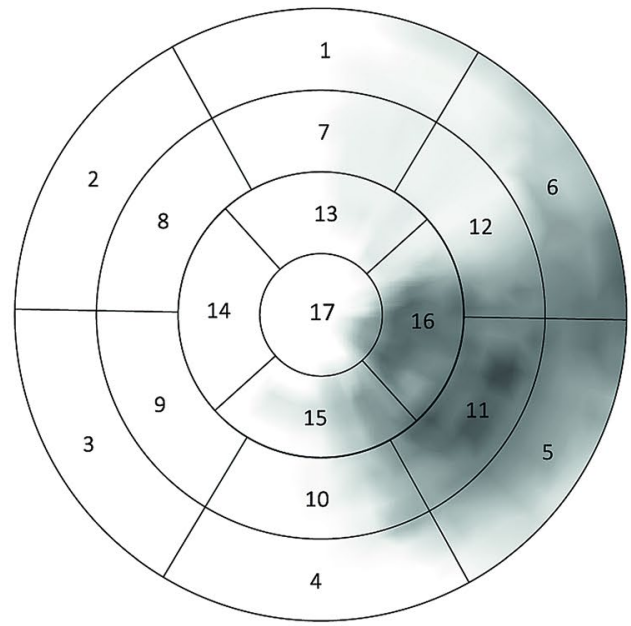

RCA 6 months

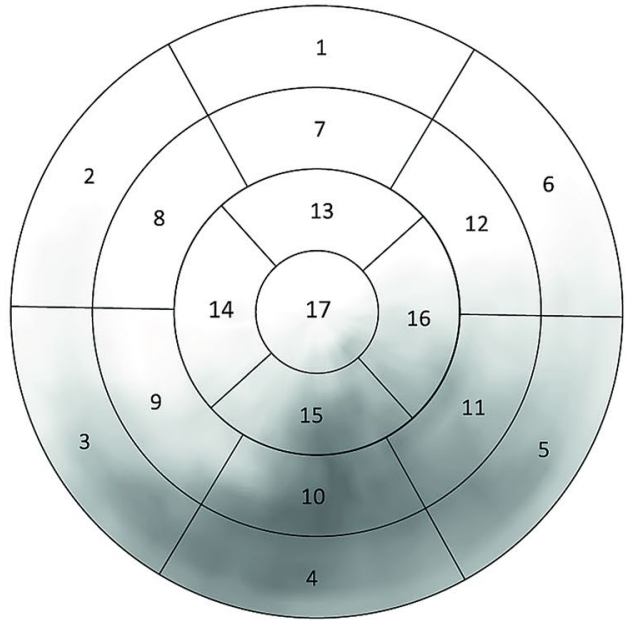

$100 \%$

$0 \%$

Fig. 2 Bullseye plots over distribution of infarction after STEMI. Polar plots of the distribution of infarction in the sub-acute and chronic phase after STEMI in the left anterior descending artery (LAD), left circumflex artery (LCx) and right coronary artery (RCA).
The grayscale intensity represents the average amount of infarction, expressed in percentage, as shown on the bar to the right with white representing $0 \%$ and black $100 \%$ infarction 
Table 1 Subject characteristics

\begin{tabular}{|c|c|c|c|}
\hline & \multicolumn{2}{|l|}{ Patients } & \multirow[t]{2}{*}{ Controls } \\
\hline & 2-6 days & 6 months & \\
\hline $\mathrm{N}$ & 77 & 77 & 27 \\
\hline Women/men & $8 / 69(10 / 90 \%)^{*}$ & $8 / 69(10 / 90 \%)^{*}$ & $8 / 19(30 / 70 \%)$ \\
\hline Age (years) & $58.2 \pm 10.2$ & & $60.7 \pm 10.7$ \\
\hline Weight $(\mathrm{kg})$ & $83.0 \pm 10.9^{*}$ & $82.2 \pm 10.9^{*}$ & $76.6 \pm 12.3$ \\
\hline HR (bpm) & $68.6 \pm 11.2 * * *$ & $61.4 \pm 9.5^{\# \# \#}$ & $61.0 \pm 7.6$ \\
\hline LVM (g) & $126.7 \pm 26.3^{*}$ & $111.8 \pm 25.8^{\# \# \#}$ & $113.2 \pm 27.8$ \\
\hline $\mathrm{EDV}(\mathrm{ml})$ & $178.6 \pm 36.5$ & 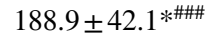 & $167.0 \pm 33.2$ \\
\hline ESV (ml) & $93.5 \pm 30.8 * * *$ & $92.2 \pm 33.8 * * *$ & $68.9 \pm 19.0$ \\
\hline $\mathrm{SV}(\mathrm{ml})$ & $85.1 \pm 16.5^{* * *}$ & $96.6 \pm 21.6^{\# \# \#}$ & $98.1 \pm 18.2$ \\
\hline $\mathrm{EF}(\%)$ & $48.5 \pm 8.3^{* * *}$ & $52.0 \pm 9.4 * * * \# \#$ & $59.1 \pm 5.2$ \\
\hline
\end{tabular}

Data expressed as mean \pm standard deviation or in absolute numbers and (percentage)

$L V M$ left ventricular mass, $L V E D V$ left ventricle end-diastolic volume, LVESV left ventricle end-systolic volume, SV stroke volume, $E F$ ejection fraction

$* \mathrm{p}<0.05$ compared to controls

$* * \mathrm{p}<0.01$ compared to controls

$* * * \mathrm{p}<0.001$ compared to controls

\# $\mathrm{p}<0.05$ compared to $2-6$ days

\#\# $\mathrm{p}<0.01$ compared to $2-6$ days

\#\#\# $\mathrm{p}<0.001$ compared to $2-6$ days

\section{Regional longitudinal strain (RLS)}

In patients with LAD infarction, RLS was impaired in all six wall regions both in the sub-acute and chronic phases after STEMI compared to controls, with a significant improvement in the chronic phase in all regions (Table 3, Fig. 5). Patients with LCx and RCA infarctions had impaired RLS in all regions except the anteroseptal wall in the sub-acute phase. In the chronic phase, LCx patients had improved RLS anterolaterally and showed no difference to controls in the inferior and inferoseptal walls. Patients with RCA infarctions also had partial recovery in the anterolateral, inferolateral, inferior and inferoseptal walls from the sub-acute to the chronic phase.

In the sub-acute phase, patients with LAD infarction had lower RLS in the anterior, anteroseptal and inferoseptal walls than patients with RCA or LCx infarction $(p<0.001$ for all), while there was no difference between RCA and LCx infarctions in these areas $(p=1.0 ; p=1.0$ and $p=0.2$, respectively). In the inferior wall region, patients with $L A D$ infarctions had worse RLS than patients with LCx infarctions $(p=0.02)$ and no difference was seen between patients with LAD and RCA infarctions $(p=0.1)$ or between RCA and LCx infarctions $(p=0.5)$. In the anterolateral and inferolateral wall, RLS did not differ between site of infarction $(\mathrm{p}=0.2$ and 1.0 , respectively).
Table 2 Global longitudinal strain and infarction size

\begin{tabular}{|c|c|c|}
\hline & GLS (\%) & IS $(\%)^{\mathrm{a}}$ \\
\hline \multicolumn{3}{|l|}{ All patients } \\
\hline 2-6 days & $-11.8 \pm 3.0 * * *$ & $17.4 \pm 9.0$ \\
\hline 6 months & $-14.3 \pm 2.9 * * * \# \# \#$ & $10.3 \pm 5.8^{\# \# \#}$ \\
\hline \multicolumn{3}{|c|}{ LAD infarction $(\mathrm{n}=28)$} \\
\hline 2-6 days & $-9.2 \pm 2.6^{* * *}$ & $23.6 \pm 8.4$ \\
\hline 6 months & $-12.8 \pm 2.9 * * * \# \# \#$ & $13.8 \pm 6.3^{\# \# \#}$ \\
\hline \multicolumn{3}{|c|}{ LCx infarction $(\mathrm{n}=10)$} \\
\hline 2-6 days & $-13.3 \pm 1.6^{* * *}$ & $13.1 \pm 5.1$ \\
\hline 6 months & $-15.3 \pm 2.5^{* * \# \#}$ & $7.3 \pm 3.6^{\# \#}$ \\
\hline \multicolumn{3}{|c|}{ RCA infarction $(n=39)$} \\
\hline 2-6 days & $-13.3 \pm 2.3 * * *$ & $14.1 \pm 7.6$ \\
\hline 6 months & $-15.0 \pm 2.7 * * * \# \# \#$ & $8.7 \pm 4.8^{\# \# \#}$ \\
\hline Controls $(\mathrm{n}=27)$ & $-18.4 \pm 2.4$ & \\
\hline
\end{tabular}

Table of infarct size (IS) global longitudinal strain (GLS) for all patients, patients divided into subgroups by culprit vessel and controls. Data expressed as mean \pm standard deviation

$L A D$ Left anterior descending artery, $L C x$ Left circumflex artery, RCA Right coronary artery

$* * \mathrm{p}<0.01$ compared to controls

$* * * \mathrm{p}<0.001$ compared to controls

$\# \#$ p $<0.01$ compared to $2-6$ days

$\# \#$ $\mathrm{p}<0.001$ compared to $2-6$ days

${ }^{\text {a }}$ Three patients had missing infarct size data at six months, why paired comparisons of IS\% was only performed with 74 patients

In the chronic phase, patients with LAD infarctions still had lower RLS than both patients with LCx and RCA infarctions in the anterior ( $\mathrm{p}=0.02$ and 0.01 , respectively) and anteroseptal walls $(\mathrm{p}=0.01$ and $\mathrm{p}=0.001$, respectively). In the inferoseptal wall, RLS was worse after infarction in the LAD than in the LCx $(p=0.007)$ but no significant difference remained compared to RCA infarctions $(p=0.08)$. No difference was seen in RLS between culprit vessels in the anterolateral $(p=0.7)$, inferolateral $(p=1.0)$ or inferior walls $(\mathrm{p}=0.6)$.

\section{Discussion}

The main result of this study was that left ventricular GLS was impaired to a greater degree after a STEMI in the LAD territory compared to LCx and RCA territory. This may in part be explained by the larger IS for the LAD-infarction. In LAD-infarction, RLS is similarly impaired in infarcted and remote myocardium, even in the chronic phase. In contrast, LCx and RCA infarction show larger impairment of RLS in the infarcted territory compared to remote. GLS is, as expected, impaired in the sub-acute phase after STEMI compared to healthy controls, and ameliorates in the first six 
A

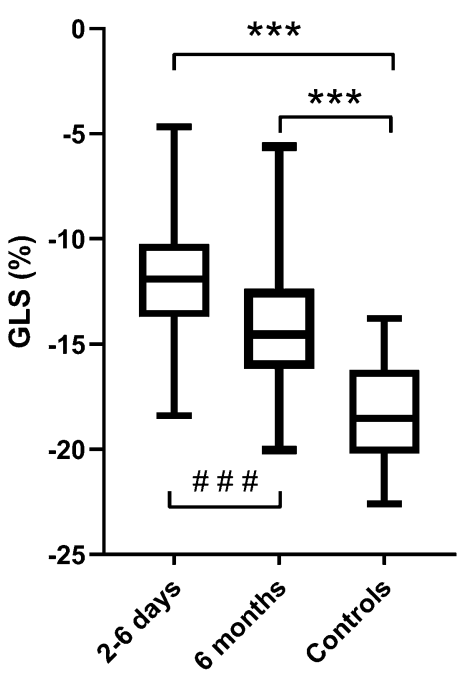

B

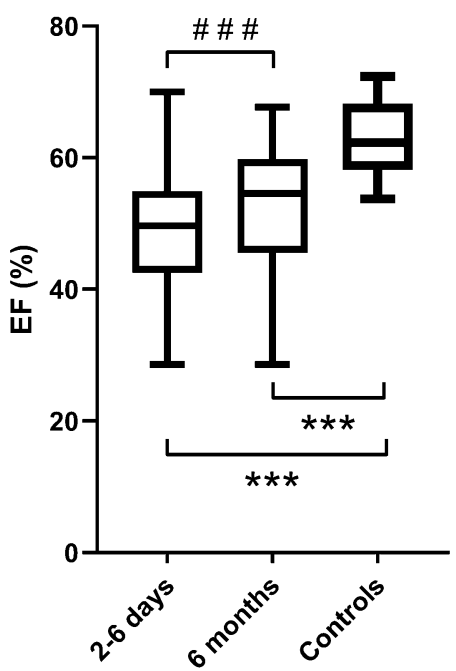

C

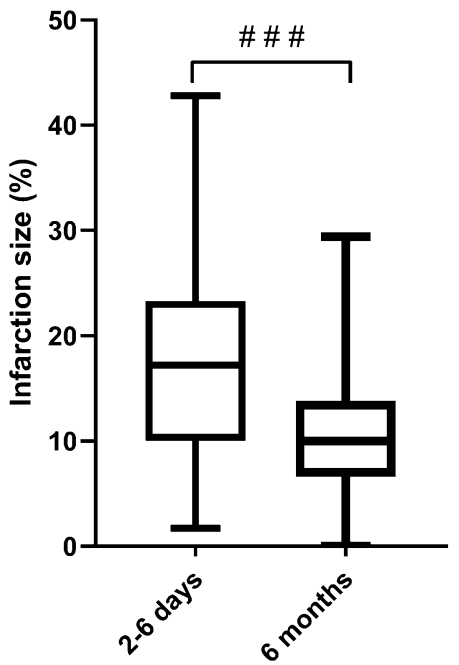

Fig. 3 Global longitudinal strain, ejection fraction and infarction size. Boxes (median and 25th and 75th percentile) with whiskers (min to max). A Global longitudinal strain (GLS) for patients at the sub-acute and chronic phase as well as healthy controls. B Ejection fraction (EF) for patients at the sub-acute and chronic phase as well as healthy controls. C Patients' infarction size at the sub-acute and chronic phase. Three patients had missing infarct size data at six months, why paired comparisons of IS\% was only performed with 74 patients. ***p $<0.001$ compared to controls. ${ }^{\# \#} \mathrm{p}<0.001$ compared to 2-6 days months, but not to the level of the controls. Further, GLS was moderately associated to IS in both the sub-acute and chronic phase, while GLS was only associated with endocardial extent of infarction in the chronic phase, and not in the sub-acute phase.

\section{Global longitudinal strain (GLS)}

GLS from FT-CMR within the first week after admission has been shown to be a strong and independent predictor of major adverse cardiac events in patients with STEMI [20]. Our findings of improved GLS at 6 months are in concordance with those of Podlesnikar et al. [23] who measured GLS with feature tracking CMR within one week and six months after anterior STEMI and found improvement after six months. Our findings are also aligned with previous studies using speckle tracking echocardiography [21, 22]. The study by Podlesnikar et al. [23] focused on GLS after anterior STEMI as a way of investigating the effect of metoprolol and did not assess IS. Our study included STEMI in all three coronary arteries and investigated RLS why it adds new knowledge about the longitudinal remodeling over time in relations to infarct location, size, and degree. Of note, our results show that LAD infarctions affect the whole left ventricle. This could explain why LAD infarcts are more detrimental than LCx and RCA infarctions and cause more heart failure [20].

\section{Regional longitudinal strain (RLS)}

The evenly distributed decrease in RLS in patients with LAD infarctions could have many potential reasons and underlying mechanisms. First, it could be due to a larger IS seen in the patients with LAD compared to patients with LCx and RCA infarctions. On the other hand, we found only a modest association of GLS and IS, why IS alone cannot explain the decreased GLS and RLS. Secondly, longitudinal strain is preload-dependent and as post-infarction remodeling is altering the preload [13], IS could indirectly through increased preload be an alternative explanation to the lower regional values in the LAD infarctions. A third explanation could be an increase of plasma catecholamine levels to compensate for the greater loss of myocardial function in LAD infarctions compared to non-LAD. An increase in cardiac sympathetic nerve activity and impaired parasympathetic function could induce a deterioration of myocardial function during the ischemic process $[35,36]$. The latter could be supported by a study by Baron et al., in which patients with acute infarction prescribed beta-adrenergic blockers at discharge had better improvement in GLS from 1 year after infarction than those without [13]. However, in a study by Karlsberg et al., there was no difference in plasma catecholamine concentrations between acute anterior and inferior infarction [37]. Instead the sympathoadrenal activation seemed to be related to the extent of the acute myocardial damage [37]. In our study, infarct extent and transmurality was not associated to GLS in the sub-acute 
A

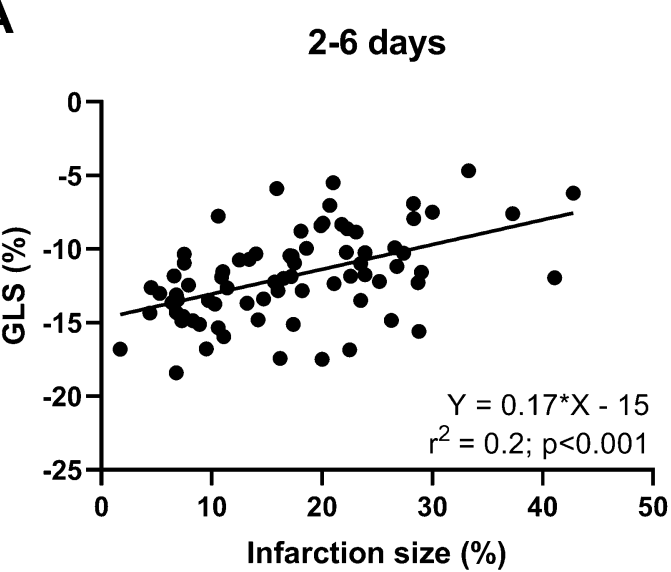

C

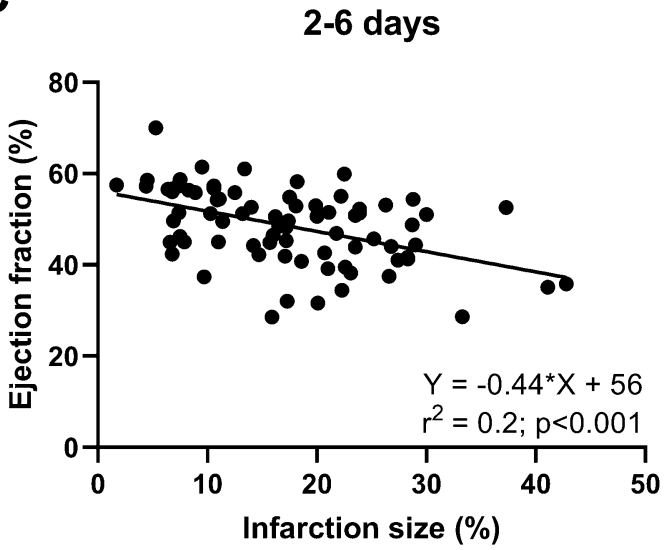

Fig. 4 Scatter plot between infarct size, global longitudinal strain and ejection fraction. Scatter plots with linear regression best fit line and coefficient of determination $\left(\mathrm{r}^{2}\right)$ for patients' infarct size vs. global

phase, which means GLS is associated to IS, but not infarct extent or transmurality in this phase. Our study is in concordance with a CMR study by Li et al. showing an association between infarct size and global strain [38]. While they found global radial, circumferential and longitudinal strain differed between patients with transmurality above or below $50 \%$ in the anterior wall myocardial infarctions, they did not find any difference in these global strain values in the non-anterior wall myocardial infarctions between the dichotomised transmurality groups. Their study differs from ours by comprising a mix of patients with acute and previous myocardial infarctions, while our study included patients with STEMI only. Furthermore, we assessed infarct size, extent and transmurality as continuous data in both the subacute and chronic phase, thereby presenting the evolution of both GLS and RLS over time after STEMI. Moreover, Li et al. used a standard deviation method for infarct assessment. Simple thresholds have shown varying results and we used a weighted intensity algorithm validated in patients and experimentally with low bias of infarct quantification [31].
B

\section{6 months}

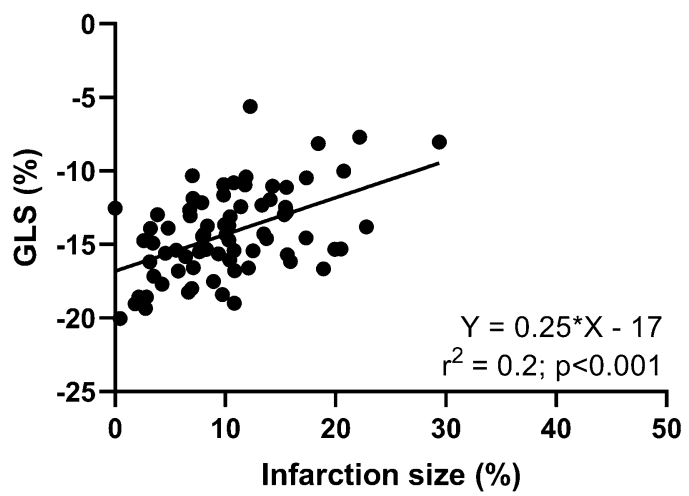

D

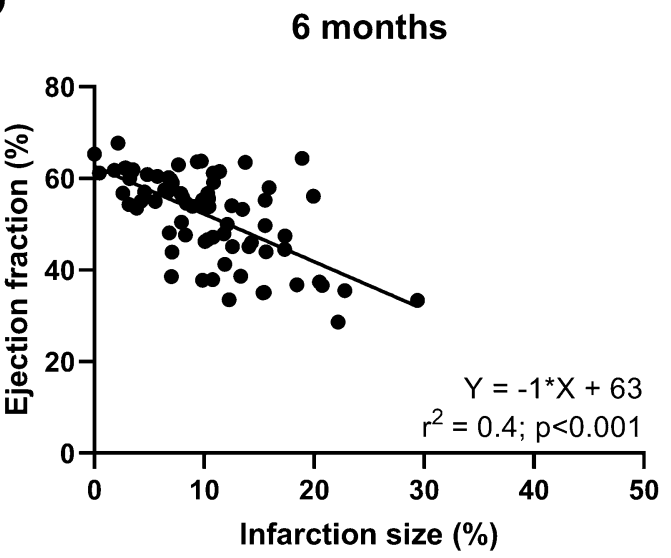

longitudinal strain (GLS) (A, B) and ejection fraction (C, D). A and C shows the sub-acute phase and B and D the chronic phase

The results from RLS are in concordance to our findings of altered regional atrioventricular plane displacement [25]. The results that impaired regional function is poorly or moderately correlated to site infarction is also in concordance with Pahlm et al. when studying wall motion in an animal setting pre and post infarction acutely [39]. Furthermore, the RLS pattern of LAD, LCx and RCA infarctions in our study aligns to some extent with the results from speckle tracking echocardiography by Biering-Sørensen et al. [36]. They also found generally reduced strain values in all six regions in patients with LAD infarction. However, they found significantly lower strain values in the culprit lesion perfusion territory of LAD, LCx and RCA, while we did not find significant difference in inferior and lateral RLS when comparing culprit lesion perfusion territory. An explanation in difference could be the time from infarction to examination. In the echocardiographic study, patients were examined 1-3 days after the STEMI, and in our study, patients were examined 2-6 days and 6 months after STEMI. A potential stunning of the myocardium could have been present in an acute phase, 
Table 3 Regional longitudinal strain by myocardial wall regions

\begin{tabular}{|c|c|c|c|c|c|c|}
\hline & Anterior & Anterolateral & Inferolateral & Inferior & Inferoseptal & Anteroseptal \\
\hline \multicolumn{7}{|c|}{ LAD infarction $(n=28)$} \\
\hline 2-6 days & $-8.8 \pm 2.5^{* * *}$ & $-12.2 \pm 4.6^{* * *}$ & $-14.2 \pm 5.4^{* * *}$ & $-10.8 \pm 4.0^{* * *}$ & $-8.7 \pm 3.2 * * *$ & $-7.4 \pm 2.9 * * *$ \\
\hline 6 months & 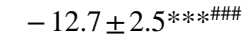 & $-15.8 \pm 3.3 * * * \# \#$ & $-17.4 \pm 5.0 * * * \# \#$ & $-15.5 \pm 4.1 * * \# \#$ & $-12.3 \pm 3.9 * * * \# \#$ & $-11.4 \pm 3.6^{* * * \# \# \# ~}$ \\
\hline \multicolumn{7}{|c|}{ LCx infarction $(n=10)$} \\
\hline $2-6$ days & $-14.9 \pm 1.7 * *$ & $-11.5 \pm 3.4 * * *$ & $-14.4 \pm 3.9^{* * *}$ & $-14.8 \pm 3.8^{* *}$ & $-14.7 \pm 2.5^{* *}$ & $-13.8 \pm 2.9$ \\
\hline 6 months & $-15.9 \pm 2.4^{*}$ & $-14.7 \pm 4.7 * * * \#$ & $-17.2 \pm 5.2 * *$ & $-17.4 \pm 4.0$ & $-16.9 \pm 3.5$ & $-15.1 \pm 2.3$ \\
\hline \multicolumn{7}{|c|}{ RCA infarction $(n=39)$} \\
\hline $2-6$ days & $-14.3 \pm 2.9 * * *$ & $-14.0 \pm 4.3^{* * *}$ & $-14.6 \pm 4.2 * * *$ & $-12.8 \pm 3.6^{* * *}$ & $-12.5 \pm 2.9 * * *$ & $-14.4 \pm 3.4$ \\
\hline 6 months & $-15.1 \pm 4.0^{* *}$ & $-16.4 \pm 4.1 * * * \#$ & $-17.4 \pm 4.4^{* * * \# \# ~}$ & 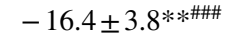 & $-14.8 \pm 3.9 * * * \# \#$ & $-14.9 \pm 3.1$ \\
\hline Controls $(n=27)$ & $-18.3 \pm 3.3$ & $-22.1 \pm 4.2$ & $-23.9 \pm 4.4$ & $-19.3 \pm 4.0$ & $-18.4 \pm 2.7$ & $-16.2 \pm 3.4$ \\
\hline
\end{tabular}

Data expressed as mean \pm standard deviation

$L A D$ Left anterior descending artery, $L C x$ Left circumflex artery, $R C A$ Right coronary artery

$* \mathrm{p}<0.05$

$* * \mathrm{p}<0.01$

$* * * \mathrm{p}<0.001$ compared to controls

\# $\mathrm{p}<0.05$

${ }^{\#} \mathrm{p}<0.01$

\#\#\# $\mathrm{p}<0.001$ compared to $2-6$ days

while it may have — at least partially — been revoked within a week. Of note, an impaired RLS in anterior septal and inferior myocardial walls, irrespective of culprit lesion perfusion territory, has been shown to have prognostic value when using echocardiography $[36,40]$ but the prognostic value of RLS from feature tracking CMR remains to be investigated.

\section{Limitations}

There were some limitations to our study. First, feature tracking CMR strain is still under development and normal values are not generally applicable for all tracking algorithms. Strain values can differ among the different vendors [41], and therefore data is not interchangeable when using different software. However, we used the same software for all strain assessment why comparison among our groups should be considered valid. Secondly, in the images from the sub-acute phase the tracking algorithm sometimes errs in tracking segments with much edema even if manual adjustments were applied. However, if insufficient tracking persisted despite adjustment, the segments/image/walls were excluded from the analysis. Thirdly, The LCx subgroup was very small with only 10 patients, which must be regarded when making conclusions about strain and IS for this subgroup. Fourth, the effect of medical therapies on GLS over time might be a potential confounder. However, data on medical therapy was not available in this study. Fifth, previous studies have emphasised the clinical usefulness and prognostic relevance of remote tissue characterization by CMR mapping post-STEMI [42]. T1 mapping or outcome were not obtained in the present study. Sixth, in this multi-centre study, cine images were acquired with 20-30 time frames according to local standards. A low frame rate could potentially affect the strain values. In a study by Backhaus et al., GLS was lower when the temporal resolution was 20 time frames compared to 30, 40 and 50 times frames in $5 \mathrm{~mm}$ and $10 \mathrm{~mm}$ slices [43]. But they found no difference in GLS regarding temporal resolution when using $8 \mathrm{~mm}$ slice thickness, such as we did in our study.

\section{Conclusion}

Global longitudinal strain is impaired sub-acutely after STEMI and improvement is seen in the chronic phase, although not reaching normal levels. Global longitudinal strain is only moderately depending on infarct size, indicating that other factors are important for ventricular function after STEMI. Even though regional longitudinal strain is most impaired in the infarcted region, remote regions can be significantly impaired in LAD infarctions, making the identification of culprit vessel from analysis of regional longitudinal strain difficult. Moreover, as LAD infarctions affect the whole heart, this could explain why LAD infarcts are more detrimental than the other culprit vessel infarctions and more often cause heart failure. 


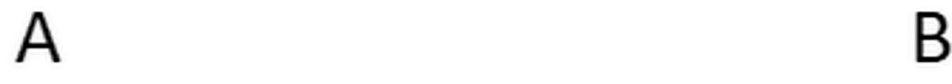

B
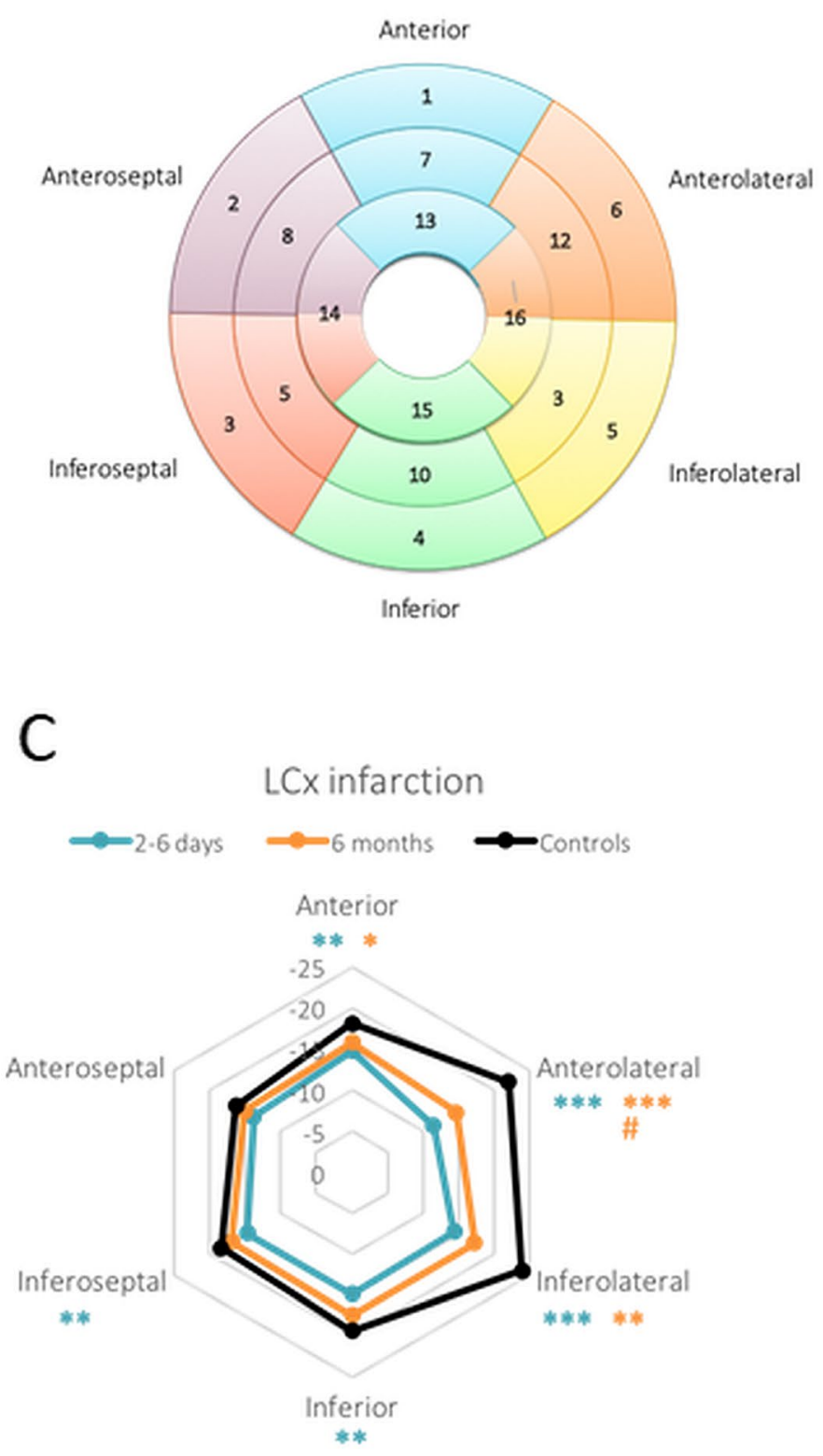

Fig. 5 Regional longitudinal strain by myocardial wall regions. Radar charts of longitudinal regional strain divided into 6 walls according to (A). Note that the apical cap (segment 17) is excluded and that segments 14 and 16 are both shared by two wall regions. B-D Chart axis (light gray) show strain, and data points show the mean strain of the segments included in the region. B Patients with STEMI in the left anterior descending artery (LAD); C Patients with STEMI in the left

Author contributions DE conceived the CHILL-MI study. EO, MC, HA, HE, EH and DE designed the study. HS, UP, MC, HA, HE, and EO analysed the data. EH created software for the study. HS, EO and MC drafted the manuscript, and all revised it. All authors read and approved the final manuscript.
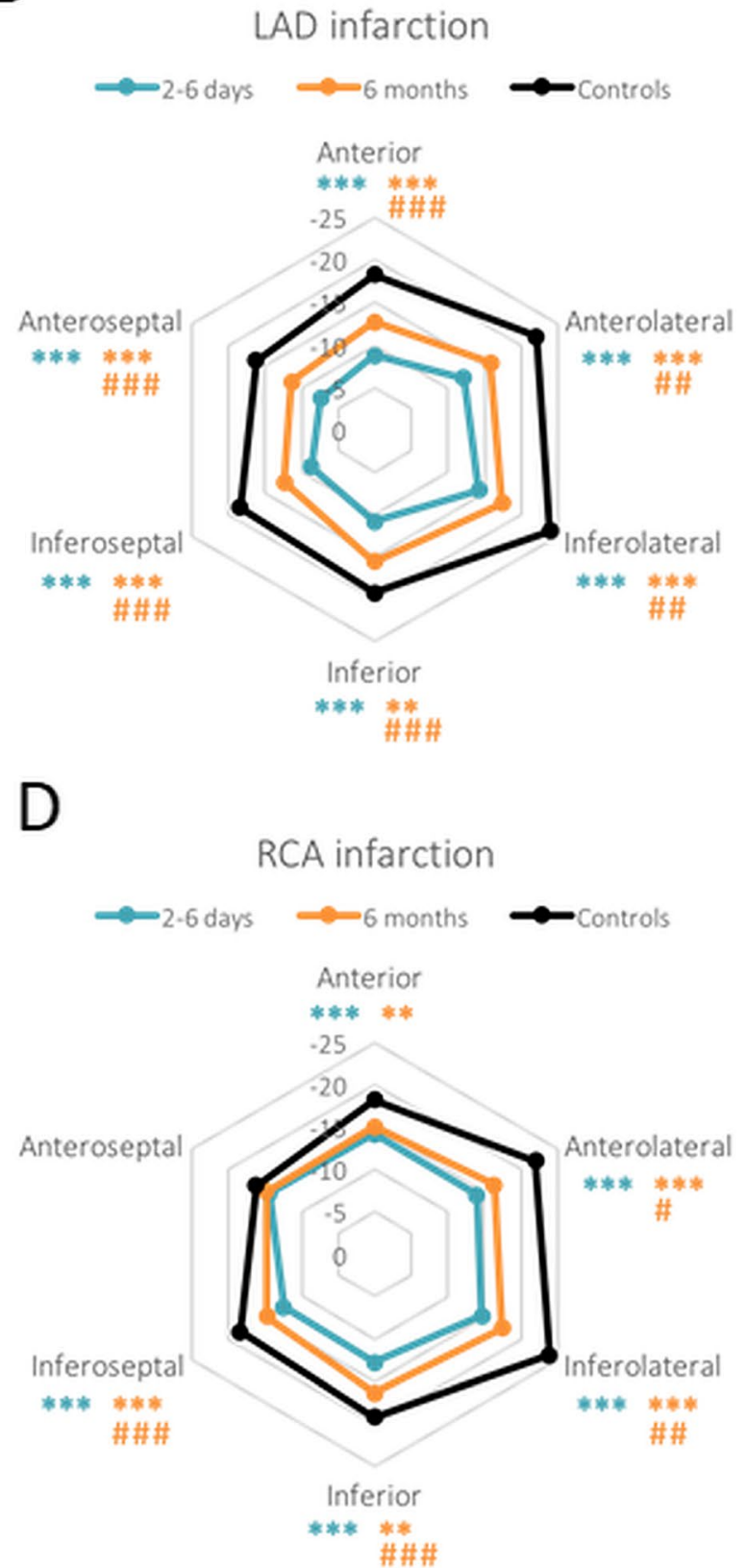

circumflex artery (LCx); D Patients with STEMI in the right coronary artery (RCA). Black represents strain values of healthy controls, blue represents strain values in STEMI patients at 2-6 days, and orange represents strain values in patients at 6 months follow up. $* \mathrm{p}<0.05$, $* * \mathrm{p}<0.01, * * * \mathrm{p}<0.001$ compared to controls. ${ }^{\#} \mathrm{p}<0.05,{ }^{\# \#} \mathrm{p}<0.01$, \#\#\# $<0.001$ compared to $2-6$ days

Funding Open access funding provided by Lund University. Swedish Research Council. Swedish Heart Lung Foundation. Lund University. Region Skåne, Southern Healthcare Region of Sweden. Wallenberg Centre for Molecular Medicine at Lund University. Crafoord Foundation. Skåne University Hospital. Philips Healthcare (San Diego, 
California) funded the CHILL-MI study but had no influence over the design or interpretation of the findings of the current study.

Data availability All relevant data are within the manuscript.

Code availability Not applicable.

\section{Declarations}

Conflict of interest $\mathrm{MC}, \mathrm{EH}, \mathrm{HE}$ and $\mathrm{HA}$ received consultancy fees from Imacor $\mathrm{AB}$ for cardiac MRI analysis in the CHILL-MI trial. HA is stock owner of Imacor AB. EH is owner of Medviso AB producing software for cardiac image analysis. Otherwise, the authors declare that they have no conflict of interest.

Ethical approval Written informed consent was obtained from all subjects in the original study. The Regional Ethical Review Board in Lund, Sweden, approved the CHILL-MI study and permission from local ethical review boards was granted at each centre.

Consent for publication Not applicable.

Open Access This article is licensed under a Creative Commons Attribution 4.0 International License, which permits use, sharing, adaptation, distribution and reproduction in any medium or format, as long as you give appropriate credit to the original author(s) and the source, provide a link to the Creative Commons licence, and indicate if changes were made. The images or other third party material in this article are included in the article's Creative Commons licence, unless indicated otherwise in a credit line to the material. If material is not included in the article's Creative Commons licence and your intended use is not permitted by statutory regulation or exceeds the permitted use, you will need to obtain permission directly from the copyright holder. To view a copy of this licence, visit http://creativecommons.org/licenses/by/4.0/.

\section{References}

1. Hartley A, Marshall DC, Salciccioli JD, Sikkel MB, Maruthappu M, Shalhoub J (2016) Trends in mortality from ischemic heart disease and cerebrovascular disease in Europe: 1980 to 2009. Circulation 133:1916-1926. https://doi.org/10.1161/CIRCULATIO NAHA.115.018931

2. Jernberg T, Johanson P, Held C, Svennblad B, Lindback J, Wallentin L, Swedeheart RHIA (2011) Association between adoption of evidence-based treatment and survival for patients with STelevation myocardial infarction. JAMA 305:1677-1684. https:// doi.org/10.1001/jama.2011.522

3. Smilowitz NR, Maduro GA Jr, Lobach IV, Chen Y, Reynolds HR (2016) Adverse trends in ischemic heart disease mortality among young new yorkers, particularly young black women. PLoS ONE 11:e0149015. https://doi.org/10.1371/journal.pone.0149015

4. Gerber Y, Jacobsen SJ, Frye RL, Weston SA, Killian JM, Roger VL (2006) Secular trends in deaths from cardiovascular diseases: a 25-year community study. Circulation 113:2285-2292. https:// doi.org/10.1161/CIRCULATIONAHA.105.590463

5. van der Bijl P, Abou R, Goedemans L, Gersh BJ, Holmes DR Jr, Ajmone Marsan N, Delgado V, Bax JJ (2020) Left ventricular post-infarct remodeling: implications for systolic function improvement and outcomes in the modern era. JACC Heart Fail 8:131-140. https://doi.org/10.1016/j.jchf.2019.08.014
6. Ibanez B, James S, Agewall S, Antunes MJ, Bucciarelli-Ducci C, Bueno H, Caforio ALP, Crea F, Goudevenos JA, Halvorsen S, Hindricks G, Kastrati A, Lenzen MJ, Prescott E, Roffi M, Valgimigli M, Varenhorst C, Vranckx P, Widimsky P, Group ESCSD (2018) 2017 ESC guidelines for the management of acute myocardial infarction in patients presenting with ST-segment elevation: the task force for the management of acute myocardial infarction in patients presenting with ST-segment elevation of the European Society of Cardiology (ESC). Eur Heart J. 39:119-77. https://doi. org/10.1093/eurheartj/ehx393

7. Dagres N, Hindricks G (2013) Risk stratification after myocardial infarction: is left ventricular ejection fraction enough to prevent sudden cardiac death? Eur Heart J 34:1964-1971. https://doi.org/ 10.1093/eurheartj/eht109

8. Bendary A, Tawfeek W, Mahros M, Salem M (2018) The predictive value of global longitudinal strain on clinical outcome in patients with ST-segment elevation myocardial infarction and preserved systolic function. Echocardiography 35:915-921. https://doi.org/10.1111/echo.13866

9. Eitel I, Stiermaier T, Lange T, Rommel KP, Koschalka A, Kowallick JT, Lotz J, Kutty S, Gutberlet M, Hasenfuss G, Thiele H, Schuster A (2018) Cardiac magnetic resonance myocardial feature tracking for optimized prediction of cardiovascular events following myocardial infarction. JACC Cardiovasc Imaging 11:1433-1444. https://doi.org/10.1016/j.jcmg.2017.11.034

10. Stokke TM, Hasselberg NE, Smedsrud MK, Sarvari SI, Haugaa KH, Smiseth OA, Edvardsen T, Remme EW (2017) Geometry as a confounder when assessing ventricular systolic function: comparison between ejection fraction and strain. J Am Coll Cardiol 70:942-954. https://doi.org/10.1016/j.jacc.2017.06.046

11. Smiseth OA, Torp H, Opdahl A, Haugaa KH, Urheim S (2016) Myocardial strain imaging: how useful is it in clinical decision making? Eur Heart J 37:1196-1207. https://doi.org/10.1093/ eurheartj/ehv529

12. Antoni ML, Mollema SA, Delgado V, Atary JZ, Borleffs CJ, Boersma E, Holman ER, van der Wall EE, Schalij MJ, Bax JJ (2010) Prognostic importance of strain and strain rate after acute myocardial infarction. Eur Heart J 31:1640-1647. https:// doi.org/10.1093/eurheartj/ehq105

13. Baron T, Christersson C, Hjorthen G, Hedin EM, Flachskampf FA (2018) Changes in global longitudinal strain and left ventricular ejection fraction during the first year after myocardial infarction: results from a large consecutive cohort. Eur Heart J Cardiovasc Imaging 19:1165-1173. https://doi.org/10.1093/ ehjci/jex260

14. Ersboll M, Valeur N, Mogensen UM, Andersen MJ, Moller JE, Velazquez EJ, Hassager C, Sogaard P, Kober L (2013) Prediction of all-cause mortality and heart failure admissions from global left ventricular longitudinal strain in patients with acute myocardial infarction and preserved left ventricular ejection fraction. J Am Coll Cardiol 61:2365-2373. https://doi.org/10.1016/j.jacc.2013. 02.061

15. Flachskampf FA, Blankstein R, Grayburn PA, Kramer CM, Kwong RYK, Marwick TH, Nagel E, Sengupta PP, Zoghbi WA, Chandrashekhar Y (2019) Global longitudinal shortening: a positive step towards reducing confusion surrounding global longitudinal strain. JACC Cardiovasc Imaging 12:1566-1567. https://doi. org/10.1016/j.jcmg.2019.03.032

16. Flachskampf FA, Chandrashekhar Y (2020) Getting shorter predicts living longer: the remarkable success of ventricular strain as a prognostic marker. JACC Cardiovasc Imaging 13:636-639. https://doi.org/10.1016/j.jcmg.2020.01.001

17. Grothues F, Smith GC, Moon JC, Bellenger NG, Collins P, Klein HU, Pennell DJ (2002) Comparison of interstudy reproducibility of cardiovascular magnetic resonance with two-dimensional echocardiography in normal subjects and in patients with heart failure 
or left ventricular hypertrophy. Am J Cardiol 90:29-34. https:// doi.org/10.1016/s0002-9149(02)02381-0

18. Chitiboi T, Axel L (2017) Magnetic resonance imaging of myocardial strain: a review of current approaches. J Magn Reson Imaging 46:1263-1280. https://doi.org/10.1002/jmri.25718

19. Gavara J, Rodriguez-Palomares JF, Valente F, Monmeneu JV, Lopez-Lereu MP, Bonanad C, Ferreira-Gonzalez I, Garcia Del Blanco B, Rodriguez-Garcia J, Mutuberria M, de Dios E, RiosNavarro C, Perez-Sole N, Racugno P, Paya A, Minana G, Canoves J, Pellicer M, Lopez-Fornas FJ, Barrabes J, Evangelista A, Nunez J, Chorro FJ, Garcia-Dorado D, Bodi V (2018) Prognostic value of strain by tissue tracking cardiac magnetic resonance after STsegment elevation myocardial infarction. JACC Cardiovasc Imaging 11:1448-1457. https://doi.org/10.1016/j.jcmg.2017.09.017

20. Reindl M, Tiller C, Holzknecht M, Lechner I, Beck A, Plappert D, Gorzala M, Pamminger M, Mayr A, Klug G, Bauer A, Metzler B, Reinstadler SJ (2019) Prognostic implications of global longitudinal strain by feature-tracking cardiac magnetic resonance in ST-elevation myocardial infarction. Circ Cardiovasc Imaging 12:e009404. https://doi.org/10.1161/CIRCIMAGING. 119.009404

21. Beitnes JO, Gjesdal O, Lunde K, Solheim S, Edvardsen T, Arnesen H, Forfang K, Aakhus S (2011) Left ventricular systolic and diastolic function improve after acute myocardial infarction treated with acute percutaneous coronary intervention, but are not influenced by intracoronary injection of autologous mononuclear bone marrow cells: a 3 year serial echocardiographic sub-study of the randomized-controlled ASTAMI study. Eur J Echocardiogr 12:98-106. https://doi.org/10.1093/ ejechocard/jeq116

22. Shehata IE, Cheng CI, Sung PH, Ammar AS, El-Sherbiny IAE, Ghanem IGA (2018) Predictors of myocardial functional recovery following successful reperfusion of acute ST elevation myocardial infarction. Echocardiography 35:1571-1578. https://doi. org/10.1111/echo.14106

23. Podlesnikar T, Pizarro G, Fernandez-Jimenez R, MonteroCabezas JM, Sanchez-Gonzalez J, Bucciarelli-Ducci C, Ajmone Marsan N, Fras Z, Bax JJ, Fuster V, Ibanez B, Delgado V (2019) Effect of early metoprolol during st-segment elevation myocardial infarction on left ventricular strain: feature-tracking cardiovascular magnetic resonance substudy from the METOCARDCNIC trial. JACC Cardiovasc Imaging 12:1188-1198. https:// doi.org/10.1016/j.jcmg.2018.07.019

24. Asgeirsson D, Hedstrom E, Jogi J, Pahlm U, Steding-Ehrenborg K, Engblom H, Arheden H, Carlsson M (2017) Longitudinal shortening remains the principal component of left ventricular pumping in patients with chronic myocardial infarction even when the absolute atrioventricular plane displacement is decreased. BMC Cardiovasc Disord 17:208. https://doi.org/10. 1186/s12872-017-0641-z

25. Pahlm U, Ostenfeld E, Seemann F, Engblom H, Erlinge D, Heiberg E, Arheden H, Carlsson M (2020) Evolution of left ventricular function among subjects with ST-elevation myocardial infarction after percutaneous coronary intervention. BMC Cardiovasc Disord 20:309. https://doi.org/10.1186/ s12872-020-01540-y

26. Pahlm U, Seemann F, Engblom H, Gyllenhammar T, Halvorsen S, Hansen HS, Erlinge D, Atar D, Heiberg E, Arheden H, Carlsson M (2018) Longitudinal left ventricular function is globally depressed within a week of STEMI. Clin Physiol Funct Imaging. https://doi.org/10.1111/cpf.12521

27. Erlinge D, Gotberg M, Lang I, Holzer M, Noc M, Clemmensen P, Jensen U, Metzler B, James S, Botker HE, Omerovic E, Engblom H, Carlsson M, Arheden H, Ostlund O, Wallentin L, Harnek J, Olivecrona GK (2014) Rapid endovascular catheter core cooling combined with cold saline as an adjunct to percutaneous coronary intervention for the treatment of acute myocardial infarction. The CHILL-MI trial: a randomized controlled study of the use of central venous catheter core cooling combined with cold saline as an adjunct to percutaneous coronary intervention for the treatment of acute myocardial infarction. J Am Coll Cardiol 63:1857-1865. https://doi.org/10.1016/j.jacc.2013. 12.027

28. Gyllenhammar T, Kanski M, Engblom H, Wuttge DM, Carlsson M, Hesselstrand R, Arheden H (2018) Decreased global myocardial perfusion at adenosine stress as a potential new biomarker for microvascular disease in systemic sclerosis: a magnetic resonance study. BMC Cardiovasc Disord 18:16. https:// doi.org/10.1186/s12872-018-0756-x

29. Simonetti OP, Kim RJ, Fieno DS, Hillenbrand HB, Wu E, Bundy JM, Finn JP, Judd RM (2001) An improved MR imaging technique for the visualization of myocardial infarction. Radiology 218:215-223. https://doi.org/10.1148/radiology.218.1.r01ja 50215

30. Heiberg E, Sjogren J, Ugander M, Carlsson M, Engblom H, Arheden H (2010) Design and validation of segment-freely available software for cardiovascular image analysis. BMC Med Imaging 10:1. https://doi.org/10.1186/1471-2342-10-1

31. Heiberg E, Ugander M, Engblom H, Gotberg M, Olivecrona GK, Erlinge D, Arheden H (2008) Automated quantification of myocardial infarction from MR images by accounting for partial volume effects: animal, phantom, and human study. Radiology 246:581-588. https://doi.org/10.1148/radiol.2461062164

32. Engblom H, Carlsson MB, Hedstrom E, Heiberg E, Ugander M, Wagner GS, Arheden H (2007) The endocardial extent of reperfused first-time myocardial infarction is more predictive of pathologic Q waves than is infarct transmurality: a magnetic resonance imaging study. Clin Physiol Funct Imaging 27:101108. https://doi.org/10.1111/j.1475-097X.2007.00723.x

33. Podlesnikar T, Pizarro G, Fernandez-Jimenez R, MonteroCabezas JM, Greif N, Sanchez-Gonzalez J, Bucciarelli-Ducci C, Marsan NA, Fras Z, Bax JJ, Fuster V, Ibanez B, Delgado $\mathrm{V}$ (2020) Left ventricular functional recovery of infarcted and remote myocardium after ST-segment elevation myocardial infarction (METOCARD-CNIC randomized clinical trial substudy). J Cardiovasc Magn Reson 22:44. https://doi.org/10. 1186/s12968-020-00638-8

34. Heyde B, Jasaityte R, Barbosa D, Robesyn V, Bouchez S, Wouters P, Maes F, Claus P, D’Hooge J (2013) Elastic image registration versus speckle tracking for 2-D myocardial motion estimation: a direct comparison in vivo. IEEE Trans Med Imaging 32:449-459. https://doi.org/10.1109/TMI.2012.2230114

35. Schomig A (1990) Catecholamines in myocardial ischemia. Systemic and cardiac release. Circulation 82:II13-II22

36. Biering-Sorensen T, Jensen JS, Pedersen SH, Galatius S, FritzHansen T, Bech J, Olsen FJ, Mogelvang R (2016) Regional longitudinal myocardial deformation provides incremental prognostic information in patients with ST-segment elevation myocardial infarction. PLoS ONE 11:e0158280. https://doi.org/ 10.1371/journal.pone.0158280

37. Karlsberg RP, Cryer PE, Roberts R (1981) Serial plasma catecholamine response early in the course of clinical acute myocardial infarction: relationship to infarct extent and mortality. Am Heart J 102:24-29. https://doi.org/10.1016/0002-8703(81) 90408-7

38. Li S, Zhao L, Lu A, Tian J, Gong L, Ma X (2020) Comparison of left ventricular global strain in anterior and non-anterior wall myocardial infarction with CMR tissue tracking. Front Physiol 11:530108. https://doi.org/10.3389/fphys.2020.530108

39. Pahlm US, Ubachs JF, Heiberg E, Engblom H, Erlinge D, Gotberg M, Arheden H (2014) Regional wall function before and after acute myocardial infarction; an experimental study in 
pigs. BMC Cardiovasc Disord 14:118. https://doi.org/10.1186/ 1471-2261-14-118

40. Wang N, Hung CL, Shin SH, Claggett B, Skali H, Thune JJ, Kober L, Shah A, McMurray JJ, Pfeffer MA, Solomon SD, Investigators V (2016) Regional cardiac dysfunction and outcome in patients with left ventricular dysfunction, heart failure, or both after myocardial infarction. Eur Heart J 37:466-472. https://doi.org/10.1093/eurheartj/ehv558

41. Barreiro-Perez M, Curione D, Symons R, Claus P, Voigt JU, Bogaert J (2018) Left ventricular global myocardial strain assessment comparing the reproducibility of four commercially available CMR-feature tracking algorithms. Eur Radiol 28:5137-5147. https://doi.org/10.1007/s00330-018-5538-4

42. Reinstadler SJ, Stiermaier T, Liebetrau J, Fuernau G, Eitel C, de Waha S, Desch S, Reil JC, Poss J, Metzler B, Lucke C, Gutberlet M, Schuler G, Thiele H, Eitel I (2018) Prognostic significance of remote myocardium alterations assessed by quantitative noncontrast T1 mapping in ST-segment elevation myocardial infarction. JACC Cardiovasc Imaging 11:411-419. https://doi. org/10.1016/j.jcmg.2017.03.015

43. Backhaus SJ, Metschies G, Billing M, Schmidt-Rimpler J, Kowallick JT, Gertz RJ, Lapinskas T, Pieske-Kraigher E, Pieske B, Lotz J, Bigalke B, Kutty S, Hasenfuss G, Kelle S, Schuster A (2021) Defining the optimal temporal and spatial resolution for cardiovascular magnetic resonance imaging feature tracking. J Cardiovasc Magn Reson 23:60. https://doi.org/10.1186/ s12968-021-00740-5

Publisher's Note Springer Nature remains neutral with regard to jurisdictional claims in published maps and institutional affiliations. 